\title{
Review
}

\section{Sprint performance under heat stress: A review}

\author{
O. Girard ${ }^{1}$, F. Brocherie ${ }^{1}$, D. J. Bishop ${ }^{2}$ \\ ${ }^{1}$ ISSUL, Institute of Sport Sciences, Department of Physiology, Faculty of Biology and Medicine, University of Lausanne, Lausanne, \\ Switzerland, ${ }^{2}$ Institute of Sport, Exercise and Active Living (ISEAL), College of Sport and Exercise Science, Victoria University, \\ Melbourne, Victoria, Australia \\ Corresponding author: Olivier Girard, PhD, ISSUL, Institute of Sport Sciences, Department of Physiology, Faculty of Biology and \\ Medicine, University of Lausanne, Building Geopolis, Campus Dorigny, CH-1015 Lausanne, Switzerland. Tel: +0041 216923760, \\ Fax: 02169232 93, E-mail: oliv.girard@gmail.com
}

Accepted for publication 28 January 2015

Training and competition in major track-and-field events, and for many team or racquet sports, often require the completion of maximal sprints in hot $\left(>30^{\circ} \mathrm{C}\right)$ ambient conditions. Enhanced short-term $(<30 \mathrm{~s})$ power output or single-sprint performance, resulting from transient heat exposure (muscle temperature rise), can be attributed to improved muscle contractility. Under heat stress, elevations in skin/core temperatures are associated with increased cardiovascular and metabolic loads in addition to decreasing voluntary muscle activation; there is also compelling evidence to suggest that large performance decrements occur when repeated-sprint exercise (consisting of brief recovery periods between sprints, usually $<60 \mathrm{~s}$ ) is performed in hot compared with cool conditions. Conversely, poorer intermittent-sprint performance (recovery periods long enough to allow near complete recovery, usually 60-300 s) in hotter conditions is solely observed when exercise induces marked hyperthermia (core temperature $>39{ }^{\circ} \mathrm{C}$ ). Here we also discuss strategies (heat acclimatization, precooling, hydration strategies) employed by "sprint" athletes to mitigate the negative influence of higher environmental temperatures.
Whether it is a direct (e.g., track-and-field sprinting events, such as 100 - to 200-m races) or indirect (e.g., team and racquet sports, cycling points races or stages with a flat finish) factor associated with performance, the ability to produce a maximal, brief/short-term effort (i.e., sprinting) is a key parameter in many competitive sports (Spencer et al., 2005). In addition, the ability to execute or repeat "all-out" sprint efforts is the focus of various training programs, such as repeated-sprint (RS) or highintensity interval training (Ferrari Bravo et al., 2008; Iaia et al., 2009; Bishop et al., 2011). Sprint performance generally refers to an "all-out" exercise bout $(\leq 10 \mathrm{~s})$, where performance can be nearly maintained until the end of the task (Girard et al., 2011). However, for the purpose of this review, our analysis focuses on "all-out" running speeds and cycling power outputs of humans in the non-sustainable range of up to $30 \mathrm{~s}$. As sprint efforts may be repeated, especially during team and racquet sports, it is also useful to define two different types of exercise: RS and intermittent-sprint (IS) exercise. RS exercise is characterized by the ability to produce short sprint bouts over a series of sprints with brief recovery periods (usually $\leq 60 \mathrm{~s}$ ) so that there is a marked performance decrement (Bishop et al., 2004; Girard et al., 2011). In comparison, bursts of maximal power during IS exercise are interspersed with recovery periods long enough (60-300 s) to allow near complete recovery of sprint performance (Balsom et al., 1992a; Duffield et al., 2009a; Girard et al., 2011).

Exercising in warm to hot $\left(25-45^{\circ} \mathrm{C}\right)$, compared with temperate to cool $\left(15-25^{\circ} \mathrm{C}\right)$, environments poses severe challenges to human regulatory systems (Galloway \& Maughan, 1997; Gonzalez-Alonso, 2012; Nybo et al., 2014), hindering endurance exercise performance in response to the development of hyperthermia (i.e., core temperature $>38.5^{\circ} \mathrm{C}$; Nybo et al., 2014). As a consequence, shorter time to exhaustion (Galloway \& Maughan, 1997; Girard \& Racinais, 2014) or longer time-trial completion time (Tatterson et al., 2000; Périard et al., 2011) is commonly associated with heat stress (Sawka et al., 2011). However, there is comparatively little research on the effects of hot ambient conditions on sprint performance. Globalization has increased the incidence of major sporting events in hot-dry and hot-humid environments, and many prestigious events require athletes to compete in equatorial (e.g., 2016 Olympic Games in Brazil) or Middle Eastern (e.g., 2022 FIFA World Cup in Qatar) regions where ambient temperatures/relative humidity (RH) levels well above $30{ }^{\circ} \mathrm{C} / 70 \% \mathrm{RH}$ may occur. Moreover, elite sprinters (e.g., Diamond League stages in Doha and Shanghai) or team-/racquet-sport players (e.g., Australian Football League, cricket in India, Australian Open tennis grand slam) regularly train or compete in conditions of high heat stress. 


\section{Girard et al.}

To date, information on the impact of heat stress on sprint performance is mostly sourced from controlled laboratory investigations. However, methodological considerations challenge the relevance of these findings given that the demands of actual competition are extremely difficult to replicate in a laboratory-based experiment. Solar radiation, wind speed or water vapor pressure [i.e., absolute humidity that is not included in Wet Bulb Globe Temperature (WBGT) calculation] is also likely to make important contributions to the degree of on-field environmental stress experienced by the "sprint" athlete (Gonzalez et al., 2012; Brocherie et al., 2014). Conversely, despite the impact of heat stress on total distance and high-intensity runs during a football game (Mohr et al., 2012), sprinting during football match presents a poor game-to-game reliability (Gregson et al., 2010). This is largely due to match-specific factors, such as tactics or the opposition, which renders the derivation of sound practical recommendations from match-play data uncertain. A combination of field and laboratory studies is therefore required to provide a clearer answer to the effects of heat stress on sprint performance.

Quantifying the extent of decrements in sprint performance under heat stress would provide coaches, performance analysts, and sports scientists with valuable knowledge to optimize athletes' preparation for competition in the heat. Therefore, the aims of this review are to: (a) provide an overview of the effects of acute heat exposure on sprint performance and the potential underpinning mechanisms during single and multiple efforts; (b) highlight some interventions to mitigate the influence of heat stress on sprint performance; and (c) discuss implications for real-world settings (sprinters and teamor racquet-sport athletes).

\section{Single-sprint performance}

Improved single-sprint (SS) performance (i.e., mean and/or peak running speed or cycling power output) can be achieved following passive local muscle heating (e.g., warm baths and/or heated blankets: Sargeant, 1987; Gray et al., 2006), active warm-up (Yaicharoen et al., 2012a, b), passive heating (e.g., elevation of core temperature by $1{ }^{\circ} \mathrm{C}$ : Linnane et al., 2004), or hot ambient conditions (e.g., heat exposure prior to exercise including an active warm-up: Falk et al., 1998; Ball et al., 1999; Yaicharoen et al., 2012c; Girard et al., 2013). Compared with normal rest, after $45 \mathrm{~min}$ of leg immersion in 12,18 , or $44{ }^{\circ} \mathrm{C}$ water baths (muscle temperatures of $36.6,29.0,31.9$, and $39.3^{\circ} \mathrm{C}$, respectively), Sargeant (1987) reported that there was an increase of $\sim 11 \%$ in maximal peak force and power during a 20 -s maximal cycling effort, while cooling the legs in 18 and $12{ }^{\circ} \mathrm{C}$ water baths resulted in reductions of $12 \%$ and $21 \%$, respectively. The magnitude of the temperature effect, however, was velocity dependent and the optimum velocity for maximum power production increased as muscle temperature rose. For example, at 54 and $140 \mathrm{rev} / \mathrm{min}$, there was a $2 \%$ and a $10 \%$ improvement in power output for every $1{ }^{\circ} \mathrm{C}$ increase in muscle temperature at $3 \mathrm{~cm}$ depth, respectively (Sargeant, 1987).

Seasonality also impacts SS performance because an environmental optimum, identified as the first week of July and the fourth week of August, exists for the setting of the 10 best annual performances in sprint and middledistance events (100-1500 m) (Haïda et al., 2014). This may in part relate to the fact that major sporting events are mainly organized in the northern hemisphere at this time of the year, where the range and mean temperatures of the different host cities are $10-38{ }^{\circ} \mathrm{C}$ and $\sim 23{ }^{\circ} \mathrm{C}$, respectively. By analyzing the mean of the top six performances of six consecutive International Association of Athletics Federations World championships (19992011), 2\% faster performance for the 100 and $200 \mathrm{~m}$ sprint events occurred in hot environment $\left(>25^{\circ} \mathrm{C}\right) \mathrm{com}-$ pared with cooler temperate conditions $\left(<25^{\circ} \mathrm{C}\right)$ (Guy et al., 2015).

The precise mechanisms by which temperature elevations may improve SS performance have not been fully delineated. A faster rate of phosphocreatine (PCr) utilization (i.e., mainly in fibers expressing predominantly myosin heavy chain IIA isoform) (Gray et al., 2006) has been proposed as an explanation for the enhanced SS performance. Conversely, passive muscle heating, through hot water immersion, may preferentially improve power output of type I (oxidative, fatigueresistant) fibers, while the contribution to power output from the type II (glycolytic, fatigue-sensitive) fibers may not change during isokinetic cycling (Sargeant \& Rademaker, 1996). A greater anaerobic adenosine triphosphate (ATP) turnover (i.e., activity of glycolytic enzymes: glycogen phosphorylase, phosphofructokinase, and lactate dehydrogenase) and adenine nucleotide degradation at high muscle temperature (Febbraio et al., 1996; Steinen et al., 1996) have also been associated with heat stress, although these findings are not specific to the sprinting literature. Another possible mechanism would be an accelerated muscle fiber conduction velocity, as individual sarcomeres become more rapidly activated at higher muscle temperatures (Farina et al., 2005; Gray et al., 2006). Reportedly, compound muscle action potentials propagate at a faster conduction velocity with an increase in skin temperature (e.g., $1.64-2.31 \mathrm{~m} / \mathrm{s} /{ }^{\circ} \mathrm{C}$ for the motor and sensory nerves from 22 to $31^{\circ} \mathrm{C}$ ) (Bolton et al., 1981).

The aforementioned biochemical and contractile adaptations of the muscle to increasing temperature will contribute to an increased cross-bridge cycling rate (Karatzaferi et al., 2004), which would in turn increase SS performance as a result of higher pedaling frequencies (Ball et al., 1999; Gray et al., 2008). After 30 min of passive heating in an environmental chamber, performing a 30 -s cycling sprint at $30{ }^{\circ} \mathrm{C}$ vs $19{ }^{\circ} \mathrm{C}$ may increase 
peak power output up to $25 \%$, corresponding to an average pedal frequency difference of $\sim 20 \mathrm{rpm}$ between conditions (Ball et al., 1999). This proposition is further supported by studies that have measured the temperature dependence of the contractile properties of muscle directly using percutaneous electrical stimulation, and the evidence of faster sequestration of $\mathrm{Ca}^{2+}$, a rightward shift in the Force-Ca ${ }^{2+}$ curve, and/or changes in the function of the ATPases (Bottinelli et al., 1996; de Ruiter \& de Haan, 2000). However, the effects of heat exposure itself on short-term power production are not universal because others have failed to report any effect of heat exposure on SS performance (Dotan \& Bar-Or, 1980; Backx et al., 2000; Bishop \& Maxwell, 2009; Yaicharoen et al., 2012c). These equivocal findings may, at least in part, relate to the myriad of confounding external (i.e., active and passive warming, heat maintenance strategies, humidity level, details of the sprint task) and internal (i.e., time of day, body composition, hydration, and nutritional status) factors that, alone or in combination, would influence the magnitude of heatrelated effects on SS performance. Furthermore, this temperature-dependent improvement in peak power is also accompanied by an approximately 1.5 times faster rate of fatigue (Sargeant, 1987; Ball et al., 1999). From a practical viewpoint, it is crucial to consider the diversity of individuals' profiles (i.e., disciplines, playing styles/ positions) because, for some athletes, their ability to produce the best possible averaged power during a given time interval, in hotter conditions, is more important for performance than generating short bursts of power within few seconds.

\section{RS performance}

Laboratory findings indicate that individuals exercising in environmental temperatures in the range of $30-35^{\circ} \mathrm{C}$ (i.e., core temperature elevations lower than $38.5^{\circ} \mathrm{C}$ ) are able to increase their RS performance presumably due to some of the muscle-related factors discussed in the Single-sprint performance section. For instance, mean power output developed during a series of five 15-s cycling sprints (with $30 \mathrm{~s}$ active recovery) was $8 \%$ higher in $35^{\circ} \mathrm{C}$ compared with $22{ }^{\circ} \mathrm{C}$ - with no noticeable differences in core temperature $\left(-37.5^{\circ} \mathrm{C}\right.$ in both conditions) and physiological markers (i.e., oxygen uptake, heart rate, blood lactate concentration) during the 60-min post-exercise recovery period (Falk et al., 1998). Under similar environmental conditions, the relative importance of neural and muscular adjustments of the knee extensors following RS cycling appears similar between hot and cool trials (end-exercise core temperatures: $38.1{ }^{\circ} \mathrm{C}$ vs $37.7^{\circ} \mathrm{C}$, respectively), despite heat exposure slightly $(\sim 3 \%)$ improving RS performance (Girard et al., 2013).

In an environmental temperature of $40{ }^{\circ} \mathrm{C}$ vs $20^{\circ} \mathrm{C}$, mean power output during the completion of a $\mathrm{RS}$ exercise $(5 \times 15 \mathrm{~s}$ sprints with $15 \mathrm{~s}$ of rest $)$ is impaired when core $\left(\sim 39.5^{\circ} \mathrm{C}\right)$ and muscle $\left(\sim 40.2^{\circ} \mathrm{C}\right.$ at a depth of $3 \mathrm{~cm})$ temperatures are simultaneously elevated as a result of $40 \mathrm{~min}$ of IS cycling in the heat (Drust et al., 2005). High core temperature therefore seems a primary factor limiting RS performance in the heat, which also negates the beneficial effect of a higher muscle temperature. In line with this suggestion, an interesting observation has been made that passive heating (i.e., water immersion at a temperature of $41{ }^{\circ} \mathrm{C}$ ) increased core $\left(\sim 39.0^{\circ} \mathrm{C}\right.$ vs $\left.37.7^{\circ} \mathrm{C}\right)$ but not muscle $\left(\sim 38.8^{\circ} \mathrm{C}\right.$ vs $39.0^{\circ} \mathrm{C}$ ) temperature prior to the first sprint compared with a control, RS performance was also impaired (Drust et al., 2005). The combined absence of differences in accumulation of metabolic fatigue agents between the hot and cool environments, and a lower force produced during a handgrip task (i.e., a muscle group not directly involved in the fatigue task), imply that marked elevations in core temperature $\left(\sim 39.5^{\circ} \mathrm{C}\right)$, negatively influencing central nervous system functioning, could explain heat-stress-related decrements in RS performance.

The negative influence of an elevated core temperature may be attributed, at least in part, to an indirect inhibitory effect of the sensory afferent feedback (group III/IV muscle afferents) originating from heated muscles (Nybo et al., 2014). In addition, any heat-related reduction in cardiac output will jeopardize arterial oxygen delivery to the exercise muscle (i.e., as consequence of lower muscle blood flow), provoking a greater reliance on anaerobic energy contribution, potentially accelerating the decline in ATP and PCr levels and aggravating muscle lactate and $\mathrm{H}^{+}$accumulation (Sawka et al., 2011). Stimulation of the metabo- and mechanoreceptors located on the end of muscle nerve afferents within the skeletal muscles, which increase circulatory and ventilatory responses, may also increase the perception of effort by possibly leading to a reduction in mental effort and thereby RS (and eventually IS) performance (Edwards et al., 2007).

Recently, match-induced declines in RS performance in fatigued football $(3 \times 30 \mathrm{~m}$ sprints separated by $25 \mathrm{~s}$ of active rest; Nybo et al., 2013) and tennis $(3 \times 15 \mathrm{~m}$ sprints separated by $15 \mathrm{~s}$ of passive rest; Girard et al., 2014) players competing in both hot $\left(35-45^{\circ} \mathrm{C}\right)$ and cool $\left(21-22{ }^{\circ} \mathrm{C}\right)$ environments have been reported. While RS performance was similarly impaired $(\sim 2 \%)$ in the two conditions immediately after a $90-\mathrm{min}$ football game, its recovery was faster after competing in the heat. Hence, RS performance was not different from baseline $24 \mathrm{~h}$ after the hot game but remained impaired until $48 \mathrm{~h}$ after playing in cool conditions (Nybo et al., 2013). In the tennis study, RS performance declined $(\sim 3 \%)$ midmatch (after $\sim 1 \mathrm{~h}$ ) with no further alterations at the end (after $\sim 2 \mathrm{~h}$ ) and full recovery within $24 \mathrm{~h}$, while matchrelated fatigue and recovery responses displayed similar patterns between the two environments (Girard et al., 


\section{Girard et al.}

2014). Despite the attainment of higher core temperatures $\left(\sim 1^{\circ} \mathrm{C}\right)$ in hotter environments, the recovery of match-related alterations in RS performance after football and tennis in hot environments seems largely related to exercise-induced rather than heat-induced factors.

Investigating the effect of time of day on RS ability, higher SS performance values - be it power output on a cycle ergometer (Racinais et al., 2005) or distance covered on a nonmotorized treadmill (Pullinger et al., 2014) - have consistently been reported in the evening than in the morning. Whereas RS performance decrement has also been reported to be larger in the evening vs in the morning (Racinais et al., 2005), others failed to observe such diurnal differences with sprint repetitions (Pullinger et al., 2014). Such discrepancies may relate to protocol differences between studies (i.e., exercise mode, number of sprints, work-to-rest ratio), training status of subjects and/or nature of the performance variables, and reliability of the fatigue resistance indices considered. Furthermore, hot conditions only seem to improve muscle contractility, muscle force, and shortduration performance in the morning when the body temperature is at its lowest (Racinais et al., 2010). Exposure to hot environments (either $1 \mathrm{~h}$ at $29.5^{\circ} \mathrm{C}$ or $30 \mathrm{~min}$ at $38^{\circ} \mathrm{C}$, with legs immersed in a hot bath), which results in an increase of $\sim 0.4{ }^{\circ} \mathrm{C}$ in rectal temperature, also blunts diurnal variation in maximal jump height and maximal sprint performance on cycle ergometer (Racinais et al., 2004, 2009).

\section{IS performance}

The detrimental effects of environmental temperatures hotter than $30^{\circ} \mathrm{C}$, compared with cool conditions, on sprint performance during IS protocols have been documented using cycle ergometry (Hayes et al., 2014), treadmill (Maxwell et al., 1996; Aldous et al., 2014), and field runs (Morris et al., 1998, 2000, 2005; Sunderland \& Nevill, 2005), i.e., limiting the strength of comparison between studies. In female hockey players, for instance, larger fatigue-induced deteriorations in the time to complete 15-m sprints and higher end-exercise rectal temperatures were reported at an environmental temperature of $30^{\circ} \mathrm{C}$ vs $19^{\circ} \mathrm{C}$ (Sunderland \& Nevill, 2005). Likewise, sprinting distance was reduced by $\sim 1.5 \%$ in the heat during a $90-\mathrm{min}$, nonmotorized treadmill soccer simulation test performed under similar environmental conditions (Aldous et al., 2014). In the two aforementioned studies, IS performance decrements were accompanied by earlier and larger increases in core temperature under heat stress, with temperatures exceeding $39.5^{\circ} \mathrm{C}$. Similar observations have been made between the rate of rise in core temperature and heatinduced reductions in IS performance, with a strong correlation reported ( $r=0.90)$ (Morris et al., 2005).

Conversely, poorer IS performance in hotter conditions may not be observed if individuals are "normothermic."
Hence, despite higher cardiovascular and perceptual strain in an environmental temperature of $40{ }^{\circ} \mathrm{C}$ vs $24^{\circ} \mathrm{C}$, in the absence of hyperthermia (average core temperature of $37.7^{\circ} \mathrm{C}$ vs $37.6^{\circ} \mathrm{C}$ in hot and cool conditions, respectively), performance during $35 \mathrm{~min}$ of IS cycling did not differ between the two environments (Almudehki et al., 2012). Similarly, in a study by Yaicharoen et al. (2012c), final values for core temperature $\left(-38.6{ }^{\circ} \mathrm{C}\right)$ may not have been high enough to unduly affect IS performance (2-min blocks consisting of a 4-s sprint followed by $100 \mathrm{~s}$ of active recovery and $10 \mathrm{~s}$ of passive rest repeated for 80 min) in $36{ }^{\circ} \mathrm{C}$ compared with $23{ }^{\circ} \mathrm{C}$ environments.

Different methods of heating the individual, for instance, passive (e.g., water immersion, warm air exposure, or heating pads) vs active hyperthermia procedures (e.g., warm-up) of various intensities/durations, have the potential to differently affect metabolite accumulation, depletion of energy stores, neuromuscular function, and/or heat storage capacity, and thereby sprint performance (Périard et al., 2014a). Investigating thermoregulatory and IS cycle performance in an environmental temperature of $36{ }^{\circ} \mathrm{C}$ after no 10 and 20 min of warmup, Bishop and Maxwell (2009) observed that a longer active warm-up procedure results in a greater endexercise increase in core temperature $(\sim 38.4,38.7$, and $39.0^{\circ} \mathrm{C}$, respectively) and a concomitant decrease in short-term RS but not prolonged IS performance. Yet, prolonged $(80 \mathrm{~min}$ ) IS performance undertaken in similarly hot environment was comparable when preceded by either an active $\left(10 \mathrm{~min}\right.$ at $\left.55 \% \mathrm{VO}_{2 \max }\right)$ or a passive (hot water bath for 10-15 min raising core temperature by $0.5^{\circ} \mathrm{C}$ ) warm-up (Yaicharoen et al., 2012c). It is notable that the peak power output of the first 4-s sprint was significantly higher after passive compared with active warm-up performed in either 36 or $23{ }^{\circ} \mathrm{C}$ conditions (no difference in core temperature: $\sim 37.7^{\circ} \mathrm{C}$ ).

By lowering the recovery intensity between sprints (50-35\% $\mathrm{VO}_{2 \max }$ ), IS performance is maintained longer (i.e., mean number of 5-s sprints interspersed with $115 \mathrm{~s}$ recovery increases by $\sim 25 \%)$ in hot-humid $\left(35^{\circ} \mathrm{C}, 80 \%\right.$ $\mathrm{RH})$ conditions, as it slows the rate of heat gain (i.e., similar peak core temperatures of $\sim 39^{\circ} \mathrm{C}$ ) (Maxwell et al., 2008). Although an increase in muscle temperature may improve power production during a short-duration cycling sprint, this difference disappears if the sprints are repeated (Falk et al., 1998; Linnane et al., 2004). With different work-to-rest ratios influencing, to a large extent, the oxidative vs glycolytic component (Balsom et al., 1992b; Tabata et al., 1997), it is intuitive (but unknown) that multiple-sprint performance may not be similarly affected by heat stress. It is anticipated that narrower exercise-to-rest ratios, inducing a decreased oxygen availability and an increased reliance on oxygenindependent glycolysis for ATP resynthesis together with a larger recruitment of fast-twitch fibers, may exacerbate sprint performance decrements in thermally challenging conditions. While it is classically reported that at a depth 
of between 1 and $4 \mathrm{~cm}$ with every $1{ }^{\circ} \mathrm{C}$ rise in muscle temperature, there is an approximate $4-10 \%$ improvement in peak power output (Bergh \& Ekblom, 1979; Sargeant, 1987), the measurement depth dependence of muscle temperature readings (Faulkner et al., 2013) further complicates our understanding of the influence of heat stress on sprint performance.

In hot-humid conditions, the ability of the body to extract heat through sweating is impaired because sweat cannot readily evaporate off the body, which will lead to greater hyperthermia and physiological strain (Sawka et al., 2011). However, no difference in performance was observed when two sets of $3 \times 30 \mathrm{~s}$ Wingates, separated by $60 \mathrm{~min}$ of passive rest were repeated in hot-humid $\left(30{ }^{\circ} \mathrm{C}, 85 \% \mathrm{RH}\right)$, hot-dry $\left(40{ }^{\circ} \mathrm{C}, 40 \% \mathrm{RH}\right)$, and cool $\left(22{ }^{\circ} \mathrm{C}, 30 \% \mathrm{RH}\right)$ environments (Backx et al., 2000). Similarly, Hayes et al. (2014) reported that $40 \mathrm{~min}$ of IS performance did not differ between hot-humid $\left(34{ }^{\circ} \mathrm{C}\right.$, $78 \% \mathrm{RH})$ and hot-dry $\left(40{ }^{\circ} \mathrm{C}, 33 \% \mathrm{RH}\right)$ environments, despite evidence of a trend toward greater physiological strain (heart rate) and higher core temperatures $\left(39.1^{\circ} \mathrm{C}\right.$ vs $38.9^{\circ} \mathrm{C}$ ) in a hot-humid environment. Despite an apparent lack of difference between hot-dry and hothumid environments, considering the importance of other weather variables (e.g., absolute humidity, wind speed, and solar radiation) (Brocherie et al., 2014) and their likely influence on thermoregulation responses, future research should carefully evaluate how they might interact to influence outdoor sprint performance.

\section{Potential strategies to mitigate the influence of heat stress on sprint performance \\ Cooling methods}

A number of pre- and during-exercise "cooling" strategies (commonly termed precooling) have been employed to mitigate the influence of exercise heat stress and the effect that associated physiological changes may have on the ability to complete a series of sprints. Intuitively, this approach is unlikely to improve, and may even be detrimental to, the performance of SS or the first few repetitions of a RS/IS test protocol (Sleivert et al., 2001; Castle et al., 2006), largely because a lower muscle temperature will reduce short-term power output (Asmussen \& Boje, 1945; Crowley et al., 1991). However, RS activity within hot environments could be enhanced by using ice packs to precool the quadriceps (e.g., -1.0 and $0.2{ }^{\circ} \mathrm{C}$ in reference to resting values for skin and core temperatures after $20 \mathrm{~min}$ of precooling, respectively; Castle et al., 2006) and mixed method approaches (involving multiple site ice pack/vest application; Minett et al., 2011, 2012). Mechanisms by which precooling interventions might improve RS performance include a greater heat storage capacity, an increased blood flow to working muscles, or reduced glycogenolysis (i.e., improved oxygen delivery and metabolite removal).
The implementation of precooling strategies could positively influence an individual behavioral thermoregulatory response. For instance, the intermittent use of an ice-cooling jacket, both before and during a RS cycling protocol in warm/humid $\left(30{ }^{\circ} \mathrm{C}, 60 \% \mathrm{RH}\right)$ conditions, reduces the perception of participants' thermal load (Duffield et al., 2003). Arguably, a meaningful improvement in effort perception may eventually enhance athlete's willingness to maintain maximal efforts during successive sprint actions. In this vein, the magnitude of the core temperature decrease and the subjective perception of recovery following cold water immersion have been related to performance enhancement in a $5 \times 40 \mathrm{~m} \mathrm{RS}$ protocol undertaken $24 \mathrm{~h}$ later (Cook \& Beaven, 2013).

However, the effects of precooling are not universal because others have failed to report any performance benefits in individuals precooled prior to RS/IS performance in the heat (Duffield et al., 2003; Cheung \& Robinson, 2004; Duffield \& Marino, 2007; Brade et al., 2013). The equivocal results seen in the literature could relate to volume- (i.e., surface area coverage; Minett et al., 2011) and/or duration- (Minett et al., 2012) dependent responses and, to a lower extent, to the variety of methods employed (i.e., cold water immersion, the wearing of ice-cooling garments/cooling jackets, application of ice packs onto the skin, ingestion of cold fluid/ ice slurry; Castle et al., 2006; Tyler et al., 2015) and the fact that the mechanisms responsible for the beneficial effects of precooling have yet to be fully elucidated. Overall, precooling methods, actively reducing core temperature by at least $\sim 0.2{ }^{\circ} \mathrm{C}$, seem beneficial to improve RS/IS performance.

\section{Acclimation/acclimatization}

While it seems that long-term heat acclimation/ acclimatization improves endurance performance (Sawka et al., 2011), the implementation of 5-7 $\times 60$ min of heat exposures may also offset some of the heat-induced aerobic performance decrement in trained athletes (Chalmers et al., 2014). This could be achieved via cardiovascular (e.g., plasma volume expansion, reduced heart rate response to submaximal exercise), thermoregulatory (e.g., decreased core temperature to exercise, increased skin blood flow for a given core temperature, decreased core temperature threshold for the onset of sweating), metabolic (e.g., attenuated carbohydrate metabolism), and perceptual (e.g., enhanced thermal comfort) adaptations. Reportedly, chronic heat exposure increases performance of high-intensity, but not maximal, intermittent running in the heat in team-sport populations (Sunderland et al., 2008; Petersen et al., 2010; Racinais et al., 2012). However, the potential of heat acclimation as an ergogenic aid for sprint exercise performance in the heat is not as clear. Sprinting speed and the decline in repeated 


\section{Girard et al.}

15-m sprint performance in female games players were similar before and after four 30-45 min exposures to $30{ }^{\circ} \mathrm{C}$ (Sunderland et al., 2008); this occurred despite a $33 \%$ increase in distance run during the post-acclimation trial, an increase in thermal comfort, and lower rectal temperature in early exercise compared with their nonacclimatized teammates (Sunderland et al., 2008). Conversely, a 10-day acclimation period, reducing resting rectal temperature by $\sim 0.4{ }^{\circ} \mathrm{C}$, resulted in a $2 \%$ increase in peak power output during a 40 -min IS protocol in the heat (Castle et al., 2011). In the absence of strong experimental evidence, caution should be exerted regarding the relevance of such protocols to improve RS/IS performance in hot environments because their efficacy may well differ between passive and active or between natural (i.e., acclimatization) and artificial (i.e., acclimation) procedures. Uncertainty also exists because the number/ implementation mode of sessions and the most suitable degree of thermal stress and exercise mode still need to be agreed on.

\section{Hydration/fluids}

Sprint and team-sport athletes are generally less concerned about the effects of hypohydration (i.e., a body water deficit; Shirreffs, 2010) than endurance athletes (Sawka et al., 2011), as supported by the essentially unaffected SS performance between dehydrated and euhydrated subjects (Watson et al., 2005; Cheuvront et al., 2006; Maxwell et al., 2009). Energy production during a SS exercise bout primarily relies on stored ATP and $\mathrm{PCr}$ energy systems, and thus does not maximally tax the cardiovascular system. However, it seems logical that maintenance of cardiovascular function - which in turn influences blood flow to exercising muscles and substrate utilization - is increasingly more important as sprint or total exercise durations lengthen or exercise-torest ratio decrease, with dehydration exacerbating the negative effects of an elevation in core temperature.

Research has reported impaired (Hickner et al., 1991; Maxwell et al., 1999; Magal et al., 2003) or unchanged (Duffield et al., 2009a; Skein \& Duffield, 2010) SS and/or RS/IS performance as a result of heat exposure and dehydration, making generalizations difficult. These equivocal results may be clouded by the impact of the variation of hydration levels tested (Yoshida et al., 2002; Maxwell et al., 2009), mode of inducing dehydration (i.e., exercise, passive heat exposure, diuretic administration; Sawka et al., 2011), and testing paradigms. Whereas dehydration as little as $\sim 2 \%$ of body weight has the potential to negatively impact aerobic performance (Sawka et al., 2011), sprint performance for 50-, 200-, and 400-m races is unchanged in cool conditions at equivalent levels of dehydration (Watson et al., 2005) because the critical level of water deficit hindering sprint performance is probably higher (3-5\%) (Yoshida et al., 2002).
There are few studies that have attempted to distinguish between the independent effects of heat exposure and dehydration upon RS/IS performance. In order to decipher the respective influence of these two factors, Kraft et al. (2011) invited 10 participants to perform six 15 -s cycle sprints with $30 \mathrm{~s}$ of active recovery on three occasions: water bath heat exposure $\left(39^{\circ} \mathrm{C}\right)$ to $3 \%$ dehydration (with fluid replacement), similar heat exposure to $3 \%$ dehydration, and a control. Their results indicated that, particularly in latter sprints, heat exposure and dehydration independently and concurrently impair peak and mean power outputs and effort perception.

\section{Implications for real-world settings}

The information gained by quantifying and explaining single- and multiple-sprint performance alterations under heat stress would provide coaches with knowledge to better prepare their athletes to train and/or compete in hot ambient conditions. While the implementation of specific strategies that may alleviate some of the heatrelated decrements for sprinters is relatively straightforward, drawing definitive conclusions for team-/ racquet-sport athletes is more problematic because sprint performance depends directly on game-type scenarios. Elite team- and racquet-sport players consistently generate core temperatures above $38.5^{\circ} \mathrm{C}$ during competition regardless of the ambient environmental conditions (Nybo et al., 2013; Périard et al., 2014b), while Australian Football League (AFL) players tolerate core temperatures up to $40.5^{\circ} \mathrm{C}$ when competing in hot conditions (Aughey et al., 2014). Under these circumstances, field observations lend support to the suggestion that players may alter their match activity patterns by reducing the volume of running undertaken in order to preserve their ability to perform high-intensity activities (Aughey et al., 2014). Football at an environmental temperature of $43{ }^{\circ} \mathrm{C}$ compared with $21^{\circ} \mathrm{C}$ is associated with declines in total game distance $(7 \%)$ and especially high-intensity running (26\%), while peak sprinting speed is improved (4\%) (Mohr et al., 2012). In the face of severe environmental challenges, players may maintain their capacity to perform the hardest actions (e.g., sprinting, accelerations) in matches by modulating the amount of low-intensity activity undertaken to ensure control of the internal heat load (Duffield et al., 2009b; Aughey et al., 2014). While these pacing strategy observations have not been experimentally proven - and, therefore, require further studies - the demonstration of the existence of a home advantage for the Gulf region countries (i.e., likely better heat acclimatized) on the outcome of international football matches in this region (Brocherie et al., 2015) adds to this notion.

Reportedly, the magnitude of exercise-induced heat stress varies considerably between individuals, most notably due to their training characteristics (type of athlete: Morris et al., 2000; aerobic fitness level: 


\section{Sprinting in hot ambient temperature}

McLellan, 2001), body composition (Jay \& Kenny, 2007), and heat acclimatization status (Chen et al., 2013; Chalmers et al., 2014). These features are in turn influenced by genetic/phenotypic variations of favorable traits associated with innate thermal tolerance and its acquirement (Taylor, 2014). In this vein, compared with cool conditions, maximal $15-\mathrm{m}$ sprints took longer to complete in the heat for well-trained female athletes with an "endurance" training background but not in their "team-sport" counterparts, as long as individuals are matched for training status (Morris et al., 2000). Furthermore, highly trained individuals generally display improved heat dissipation and tolerance due to lower temperature thresholds for vasodilation and sweating (Mora-Rodriguez, 2012). Conversely, body fatness may account for a faster increase in body temperature at a given metabolic rate (Jay \& Kenny, 2007), but more research is needed to endorse the suggestion that larger athletes will be at a disadvantage when sprinting in the heat. While sprint-interval (repeated Wingate) and endurance (cycling at $65 \% \mathrm{VO}_{2 \max }$ ) training for 2 weeks both induced $\sim 10 \%$ improvements in aerobic fitness and decreased cardiovascular strain during heat stress testing, neither elicited changes in mean sweat loss and the rise in core temperature and did not replace heat acclimatization (McGarr et al., 2014). After five daily sessions of upright leg cycling exercise in the heat, heatacclimated athletes showed a $6.6 \%$ increase in endurance time to exhaustion in a hot environment (Chen et al., 2013). However, no performance amelioration occurred in non-heat-acclimatized athletes, while both groups also failed to display any improvement between pre- and posttests when tested in cool conditions (Chen et al., 2013). In team sports, whether larger improvements in sprint performance following short-term heat acclimation are also evident in hotter competition conditions is unknown (Chalmers et al., 2014).

While evidence exists for the efficacy of ingesting fluids containing carbohydrate during continuous runs in the heat (Millard-Stafford et al., 1992), its impact on delaying the onset of fatigue during intermittent exercises that includes maximal bursts of activity is more circumstantial. Although drinking a $6.5 \%$ carbohydrateelectrolyte solution induced greater metabolic changes than flavored water and placebo solutions, the ability of unacclimated males to perform prolonged intermittent high-intensity shuttle running in a hot environment was not improved (Morris et al., 2003). In tennis players competing for $\sim 2 \mathrm{~h}$ in a hot environment, match-induced impairments in 15-m SS and RS performance were not influenced by an individualized hydration regimen based on undertaking play euhydrated, standardizing sodium intake and minimizing body mass losses (Périard et al., 2014b). Conversely, creatine supplementation augmented performance during three consecutive 10-s sprints separated by $50 \mathrm{~s}$ in $37^{\circ} \mathrm{C}$, without altering thermoregulatory responses (Volek et al., 2001). The lack of definitive conclusions about the effects of fluid ingestion and heat stress upon sprint performance can be attributed to external factors such as the sprint duration, the type of recovery, the number of sprint repetitions, the quantity and rate of fluid ingestion, and the degree of heat exposure. Nonetheless, too large an increase in core temperature due to excessive warm-up durations, or exercising at an excessively high intensity, augments the reliance on carbohydrate use during prolonged heat stress exercise (Febbraio, 2001). Team-sport athletes should therefore minimize their increase in core temperature before competing in hot ambient conditions by reducing warm-up and heat exposure, so as not to induce earlier and larger performance decrements. Hence, although not yet researched, an early depletion of muscle glycogen concentration and an extra heat load could decrease multiple-sprint performance of team-sport athletes during the most intense phase of a game or toward the end of a match.

Wearing protective clothing, for instance, as American footballers do, decreases the effectiveness of heat loss mechanisms (Sawka et al., 2011). The addition of a uniform exaggerates perceptual ratings, skin and core temperatures at a given workload, and decreases the amount of exercise an individual can safely perform (Johnson et al., 2010). While this microclimate may predispose to exertional heat illness, particularly if a competition is played with a high level of heat stress, the impact of protective clothing on repeated short-term power production remains under researched (Havenith et al., 2012). Furthermore, as team-sport players such as footballers may be unaffected in the early periods of a game played with elevated heat stress, but perform at less than maximal capacity toward its end, strategies around fluid replacement using an individualized approach could be decisive (Maughan et al., 2010). In practice, however, such "re-hydration breaks" are only rarely implemented (e.g., only during the United StatesPortugal match in the first round of the 2014 FIFA World Cup). This approach is facilitated in sport activities, such as tennis, AFL, beach volleyball, or field hockey offering longer and/or more frequent breaks, as well as player turnover, during competition to reduce exertional heat illness risk to the players.

By reducing the drop in muscle temperature during a 30-min post-warm-up period, through the use of insulated athletic pants with a heating element, "passive" heat maintenance has successfully been implemented to improve subsequent peak power output during a maximal 30-s cycling sprint (Faulkner et al., 2013). In professional rugby league players completing six $40-\mathrm{m}$ shuttle sprints separated by $20 \mathrm{~s}$ of passive recovery, wearing a "passive" heat maintenance blizzard survival jacket over a 15-min period after warming-up improved RS performance (i.e., fastest, mean, and total sprint times) compared with a control condition (Kilduff et al., 2013). In football, both muscle and core temperatures 


\section{Girard et al.}

$\left(\sim 1.1\right.$ and $2{ }^{\circ} \mathrm{C}$, respectively) markedly decrease during the 15 -min half-time break when players recover passively, which is associated with an $\sim 2.5 \%$ decline in RS performance (Mohr et al., 2004). However, when players rewarmed by performing $7 \mathrm{~min}$ of moderate-intensity exercise prior to the second half, the body temperatures were maintained and the sprint performance did not deteriorate. More recently, a re-warm-up phase including five-repetition leg-press exercise was shown to improve subsequent RS performance during an intermittent teamsport activity (Zois et al., 2013). While "passive" heat maintenance strategies are potentially beneficial in preparing some athletes (e.g., between warm-up end and competition heat in sprinters) for short-term "sprint"based activities (i.e., greater preservation of temperaturerelated warm-up mechanisms), such practices should however be carefully controlled with others (e.g., tennis players who may compete for several hours) so as not to become counterproductive in situations of elevated heat stress (Russel et al., 2015). Practically, it may be more efficient for team-sport players to cool down during breaks into competition, for instance, during halftime in footballers, so that in the long term sprint performance will be better maintained for the entire second half.

\section{Conclusions}

The muscle temperature rise associated with acute heat exposure may benefit SS (short-term power output) or initial-sprint bouts performance during a multiple-sprint task via an improved muscle contractility. With the repetition of efforts, however, there comes a point where those muscle-temperature-related benefits are overridden by the exacerbated cardiovascular and metabolic strain and decreasing voluntary muscle activation associated with greater elevation in core temperature in hotter environments. Larger performance decrements occur when RS exercises are performed with exacerbated heat stress. Conversely, poorer IS performance in hotter conditions is solely observed when exercise induces marked hyperthermia (core temperature $>39^{\circ} \mathrm{C}$ ). In an attempt to obtain physiological adaptations lowering thermal strain and improving the ability to complete a series of sprints in the heat, athletes could implement internal/external cooling methods, heat acclimation protocols, and/or strategies around fluid replacement using an individualized approach. However, the usefulness of these practices for improvement of SS performance in a hot environment must be questioned.

\section{Perspectives}

With respect to sport-specific fitness of team-/racquetsport players, growing evidence indicates that larger improvements in RS ability are possible following RS training conducted in hypoxia compared with matched training (sprint number) in normoxia (Faiss et al., 2013). Recently, the concept of cross-tolerance - i.e., acclimation to one environmental stressor (i.e., heat) could enhance adaptation to various other stressors (i.e., hypoxia or vice versa) - has emerged as a time-efficient solution, as it is believed to activate common protective pathways (i.e., HIF-1 $\alpha$ pathway, expansion of plasma volume, or improved cardiac efficiency; White et al., 2014). While this may potentially increase and/or speed up competition preparation of "sprint" athletes engaged in sporting events scheduled in challenging environmental conditions, evidence of the efficacy of the crosstolerance concept is lacking. Therefore, at this time, there is no support for the prescription of repeated sprinting in hypoxia (over "traditional" normoxic methods or in combination with other methods using heat/hypoxic stresses) for "sprint" athletes who are going to compete in hot conditions, but this is an interesting area for future research.

Key words: Hyperthermia, thermoregulation, temperature, repeated-sprint ability, sprinting, accelerated runs, heat acclimatization, fatigue.

\section{Acknowledgements}

The authors are grateful to Dr. Sébastien Racinais and Dr. Julien Périard for the opportunity given to present the work that has formed the basis of this article during the "Training \& competing in the heat" conference (Doha, Qatar - 23-24 March 2014). We would also like to gratefully acknowledge their editorial comments and suggestions in the revision of this manuscript.

Conflicts of interest: The authors of this study declare that they have no conflicts of interest.

\section{References}

\footnotetext{
Aldous JW, Chrismas BC, Beel L, Akubat

I, Dascombe B, Taylor L. Hot environment mediated decrements in soccer-specific capacity utilising a non-motorised treadmill soccer-specific simulation (ispt). In: Favero T, Lechler L, Conte D, Stavrianeas S, Guest A, eds. 4th World Conference on Science and Soccer (WCSS). Portland: University of Portland OR (USA), 2014: 24.
}

Almudehki F, Girard O, Grantham J, Racinais S. Hot ambient conditions do not alter intermittent cycling sprint performance. J Sci Med Sport 2012: 15 (2): 148-152.

Asmussen E, Boje O. Body temperature and capacity for work. Acta Physiol Scand 1945: 10 (1): 1-22.

Aughey RJ, Goodman CA, McKenna MJ. Greater chance of high core temperatures with modified pacing strategy during team sport in the heat. J Sci Med Sport 2014: 17 (1): 113-118. Backx K, McNaughton L, Crickmore L, Palmer G, Carlisle A. Effects of differing heat and humidity on the performance and recovery from multiple high intensity, intermittent exercise bouts. Int J Sports Med 2000: 21: 400-405. 
Sprinting in hot ambient temperature

Ball D, Burrows C, Sargeant AJ. Human power output during repeated sprint cycle exercise: the influence of thermal stress. Eur J Appl Physiol 1999: 79: 360-366.

Balsom PD, Seger JY, Sjodin B, Ekblom B. Physiological responses to maximal intensity intermittent exercise. Eur J Appl Physiol Occup Physiol 1992b: 65 (2): 144-149.

Balsom PD, Seger JY, Sjödin B, Ekblom B. Maximal-intensity intermittent exercise: effect of recovery duration. Int J Sports Med 1992a: 13 (7): 528-533.

Bergh U, Ekblom B. Influence of muscle temperature on maximal muscle strength and power output in human skeletal muscles. Acta Physiol Scand 1979: 107 (1): 33-37.

Bishop D, Edge J, Davis C, Goodman C. Induced metabolic alkalosis affects muscle metabolism and repeated-sprint ability. Med Sci Sports Exerc 2004: 36 (5): 807-813.

Bishop D, Girard O, Mendez-Villanueva A. Repeated-sprint ability - Part II. Recommendations for training. Sports Med 2011: 41 (9): 741-756.

Bishop D, Maxwell N. Effects of active warm up on thermoregulation and intermittent-sprint performance in hot conditions. J Sci Med Sport 2009: 12 (1): 196-204.

Bolton CF, Sawa GM, Carter K. The effects of temperature on human compound action potentials. J Neurol Neurosurg Psychiatry 1981: 44 (5): 407-413.

Bottinelli R, Canepari M, Pellegrino MA, Reggiani C. Force-velocity properties of human skeletal muscle fibres: myosin heavy chain isoform and temperature dependence. J Physiol 1996: 495 (Pt 2): 573-586.

Brade C, Dawson B, Wallman K. Effect of pre-cooling and acclimation on repeated-sprint performance in heat. J Sports Sci 2013: 31 (7): 779-786.

Brocherie F, Girard O, Farooq A, Millet GP. Influence of weather, rank, and home advantage on football outcomes in the Gulf region. Med Sci Sports Exerc 2015: 47 (2): 401-410.

Brocherie F, Girard O, Pezzoli A, Millet GP. Outdoor exercise performance in ambient heat: time to overcome challenging factors? Int J Hyperthermia 2014: 30 (8): 547-549.

Castle P, Macdonald AL, Philp A, Webborn ADJ, Watt PW, Maxwell N. Precooling leg muscle improves intermittent sprint exercise performance in hot, humid conditions. J Appl Physiol 2006: 100 (4): 1377-1384.

Castle P, Mackenzie RW, Maxwell N, Webborn ADJ, Watt PW. Heat acclimation improves intermittent sprinting in the heat but additional pre-cooling offers no further ergogenic effect. J Sports Sci 2011: 29 (11): 1125-1134.

Chalmers S, Esterman A, Eston R, Bowering KJ, Norton K. Short-term heat acclimation training improves physical performance: a systematic review, and exploration of physiological adaptations and application for team sports. Sports Med 2014: 44 (7): 971-988.

Chen TI, Tsai PH, Lin JH, Lee NY, Liang MTC. Effect of short-term heat acclimation on endurance time and skin blood flow in trained athletes. Open Access J Sports Med 2013: 4: 161-170.

Cheung SS, Robinson AM. The influence of upper-body pre-cooling on repeated sprint performance in moderate ambient temperatures. J Sports Sci 2004: 22 (7): 605-612.

Cheuvront SN, Carter R III, Haymes EM, Sawka MN. No effect of moderate hypohydration or hyperthermia on anaerobic exercise performance. Med Sci Sports Exerc 2006: 38 (6): 1093-1097.

Cook CJ, Beaven CM. Individual perception of recovery is related to subsequent sprint performance. Br J Sports Med 2013: 47 (11): 705-709.

Crowley GC, Lohn MS, Van Someren N, Wade AJ. Effects of cooling the legs on performance in a standard Wingate anaerobic power test. Br J Sports Med 1991: 25 (4): 200-203.

de Ruiter CJ, de Haan A. Temperature effect on the force/velocity relationship of the fresh and fatigued human adductor pollicis muscle. Pflugers Arch 2000: 440 (1): 163-770.

Dotan R, Bar-Or O. Climatic heat stress and performance in the Wingate anaerobic test. Eur J Appl Physiol 1980: 44 (3): 237-243.

Drust B, Rasmussen P, Mohr M, Nielsen B, Nybo L. Elevations in core and muscle temperature impairs repeated sprint performance. Acta Physiol Scand 2005: 183 (2): 181-190.

Duffield R, Coutts AJ, Quinn J. Core temperature responses and match running performance during intermittent-sprint exercise competition in warm conditions. J Strength Cond Res 2009b: 23 (4): 1238-1244.

Duffield R, Dawson B, Bishop D, Fitzsimons M, Lawrence S. Effect of wearing an ice cooling jacket on repeat sprint performance in warm/humid conditions. Br J Sports Med 2003: 37 (2): 164-169.

Duffield R, King M, Skein M. Recovery of voluntary and evoked muscle performance following intermittent-sprint exercise in the heat Int J Sports Physiol Perform 2009a: 4 (2): 254-268

Duffield R, Marino F. Effects of pre-cooling procedures on intermittent-sprint exercise performance in warm conditions. Eur J Appl Physiol 2007: 100 (6): 727-735.

Edwards AM, Mann ME, Marfell-Jones MJ, Rankin DM, Noakes TD, Shillington DP. Influence of moderate dehydration on soccer performance: physiological responses to $45 \mathrm{~min}$ of outdoor match-play and the immediate subsequent performance of sport-specific and mental concentration tests. Br J Sports Med 2007: 41 (6): 385-391.

Faiss R, Girard O, Millet GP. Advancing hypoxic training in team sports: from intermittent hypoxic training to repeated sprint training in hypoxia. $\mathrm{Br} \mathrm{J}$ Sports Med 2013: 47 (1): 47-50.

Falk B, Radom-Isaac S, Hoffmann JR, Wang Y, Yarom Y, Magazanik A, Weinstein Y. The effect of heat exposure on performance of and recovery from high-intensity, intermittent exercise. Int J Sports Med 1998: 19 (1): 1-6.

Farina D, Ardent-Nielsen L, Graven-Nielsen T. Effect of temperature on spike-triggered average torque and electrophysiological properties of low-threshold motor units. J Appl Physiol 2005: 99 (1): 197-203.

Faulkner SH, Ferguson RA, Gerrett N, Hupperets M, Hodder SG, Havenith G. Reducing muscle temperature drop after warm-up improves sprint cycling performance. Med Sci Sports Exerc 2013: 45 (2): 359-365.

Febbraio MA. Alterations in energy metabolism during exercise and heat stress. Sports Med 2001: 31 (1): 47-59.

Febbraio MA, Carey MF, Snow RJ, Stathis CG, Hargreaves M. Influence of elevated muscle temperature on metabolism during intense, dynamic exercise. Am J Physiol 1996: 271 (5 Pt 2): R1251-R1255.

Ferrari Bravo D, Impellizzeri FM, Rampinini E, Castagna C, Bishop D, Wisloff U. Sprint vs interval training in football. Int J Sports Med 2008: 29 (8): 668-674.

Galloway SD, Maughan RJ. Effects of ambient temperature on the capacity to perform prolonged cycle exercise in man. Med Sci Sports Exerc 1997: 29 (9): 1240-1249.

Girard O, Bishop DJ, Racinais S. Hot conditions improve power output during repeated cycling sprints without modifying neuromuscular fatigue characteristics. Eur J Appl Physiol 2013: 113 (2): 359-369. 


\section{Girard et al.}

Girard O, Christian RJ, Racinais S, Périard J. Heat stress does not exacerbate tennis-induced alterations in physical performance. Br J Sports Med 2014: 48 (1): i39-i44.

Girard O, Mendez-Villanueva A, Bishop DJ. Repeated-sprint ability - Part 1. Factors contributing to fatigue. Sports Med 2011: 41 (8): 673-694.

Girard O, Racinais S. Combining heat stress and moderate hypoxia reduces cycling time to exhaustion without modifying neuromuscular fatigue characteristics. Eur J Appl Physiol 2014: 114 (7): 1521-1532.

Gonzalez RR, Cheuvront SN, Ely BR, Moran DS, Hadid A, Endrusick TL, Sawka MN. Sweat rate prediction equations for outdoor exercise with transient solar radiation. J Appl Physiol 2012: 112 (8): 1300-1310.

Gonzalez-Alonso J. Human thermoregulation and the cardiovascular system. Exp Physiol 2012: 97 (3): 340-346.

Gray SR, De Vito G, Nimmo MA, Farina D, Ferguson RA. Skeletal muscle ATP turnover and muscle fiber conduction velocity are elevated at higher muscle temperatures during maximal power output development in humans. Am J Physiol Regul Integr Comp Physiol 2006: 290 (2): R376-R382.

Gray SR, Söderlund K, Ferguson RA. ATP and phosphocreatine utilization in single human muscle fibres during the development of maximal power output at elevated muscle temperatures. J Sports Sci 2008: 26 (7): 701-707.

Gregson W, Drust B, Atkinson G, Di Salvo V. Match-to-match variability of high speed activities in premier league soccer. Int J Sports Med 2010: 31 (4): 237-242.

Guy JH, Deakin GB, Edwards AM, Miller CM, Pyne DB. Adaptation to hot environmental conditions: an exploration of the performance basis, procedures and future directions to optimise opportunities for elite athletes. Sports Med 2015. [Epub ahead of print]. doi: 10.1007/s40279014-0277-4

Haïda A, Dor F, Guillaume M, Quinquis L, Marc A, Marquet LA,

Antero-Jacquemin J, Tourny-Chollet C, Desgorces F, Berthelot G, Toussaint JF. Environment and scheduling effects on sprint and middle distance running performance. PLoS ONE 2014: 8: e79548.

Havenith G, Fiala D, Błazejczyk K, Richards M, Bröde P, Holmér I, Rintamaki H, Benshabat Y, Jendritzky G. The UTCI-clothing model. Int J Biometeorol 2012: 56 (3): 461-470.

Hayes M, Castle PC, Ross EZ, Maxwell NS. The influence of hot humid and hot dry environments on intermittent-sprint exercise performance. Int J Sports Physiol Perform 2014: 9 (3): 387-396.

Hickner RC, Horswill CA, Welker JM, Scott J, Roemmich JN, Costill DL. Test development for the study of physical performance in wrestlers following weight loss. Int J Sports Med 1991: 12 (6): 557-562.

Iaia FM, Rampinini E, Bangsbo J. High-intensity training in football. Int $\mathbf{J}$ Sports Physiol Perform 2009: 4 (3): 291-306.

Jay O, Kenny GP. The determination of changes in body heat content during exercise using calorimetry and thermometry. J Hum Environ Syst 2007: 10 (1): 19-29.

Johnson EC, Ganio MS, Lee EC, Lopez RM, McDermott BP, Casa DJ, Maresh CM, Armstrong LE. Perceptual responses while wearing an American Football uniform in the heat. J Athl Train 2010: 45 (2): 107-116.

Karatzaferi C, Chinn MK, Cooke R. The force exerted by a muscle cross-bridge depends directly on the strength of the actomyosin bond. Biophys J 2004: 87 (4): 2532-2544.

Kilduff LP, West DJ, Williams N, Cook CJ. The influence of passive heat maintenance on lower body power output and repeated sprint performance in professional rugby league players. J Sci Med Sport 2013: 16 (5): 482-486.

Kraft JA, Green JM, Bishop PA, Richardson MT, Neggers YH, Leeper JD. Effects of heat exposure and 3\% dehydration achieved via hot water immersion on repeated cycle sprint performance. J Strength Cond Res 2011: 25 (3): 778-786.

Linnane DM, Bracken RM, Brooks S, Cox VM, Ball D. Effects of hyperthermia on the metabolic responses to repeated high-intensity exercise. Eur J Appl Physiol 2004: 93 (1-2): 159-166.

Magal M, Webster MJ, Sistrunk LE, Whitehead MT, Evans RK, Boyd JC. Comparison of glycerol and water hydration regimens on tennis-related performance. Med Sci Sports Exerc 2003: 35 (1): 150-156.

Maughan RJ, Shirreffs SM, Ozgünen KT, Kurdak SS, Ersöz G, Binnet MS, Dvorak J. Living, training and playing in the heat: challenges to the football player and strategies for coping with environmental extremes. Scand J Med Sci Sports 2010: 20 (3): 117-124.

Maxwell NS, Aitchison TC, Nimmo MA. The effect of climatic stress on intermittent supramaximal running performance in humans. Exp Physiol 1996: 81 (5): 833-845.

Maxwell NS, Castle PC, Spencer M. Effect of recovery intensity on peak power output and the development of heat strain during intermittent sprint exercise while under heat stress. J Sci Med Sport 2008: 11 (5): 491-499.

Maxwell NS, Gardner F, Nimmo MA. Intermittent running: muscle metabolism in the heat and effect of hypohydration. Med Sci Sports Exerc 1999: 31 (5): 675-683.

Maxwell NS, McKenzie RW, Bishop D. Influence of hypohydration on intermittent sprint performance in the heat. Int J Sports Physiol Perform 2009: 4 (1): 54-67.

McGarr GW, Hartley GL, Cheung SS. Neither short-term sprint nor endurance training enhances thermal response to exercise in a hot environment. J Occup Environ Hyg 2014: 11 (1): 47-53.

McLellan TM. The importance of aerobic fitness in determining tolerance to uncompensable heat stress. Comp Biochem Physiol A Mol Integr Physiol 2001: 128 (4): 691-700.

Millard-Stafford ML, Sparling PB, Rosskopf LB, DiCarlo LJ. Carbohydrate-electrolyte replacement improves distance running performance in the heat. Med Sci Sports Exerc 1992: 24 (8): 934-940.

Minett G, Duffield R, Marino F, Portus M. Duration-dependant response of mixed-method pre-cooling for intermittent-sprint exercise in the heat. Eur J Appl Physiol 2012: 112 (10): 3655-3666.

Minett GM, Duffield R, Marino F, Portus $\mathrm{M}$. Volume-dependent response of precooling for intermittent-sprint exercise in the heat. Med Sci Sports Exerc 2011: 43 (9): 1760-1769.

Mohr M, Krustrup P, Nybo L, Nielsen J, Bangsbo J. Muscle temperature and sprint performance during soccer matches - beneficial effect of re-warm-up at half-time. Scand J Med Sci Sports 2004: 14 (3): 156-162.

Mohr M, Nybo L, Grantham J, Racinais S. Physiological responses and physical performance during football in the heat. PLoS ONE 2012: 7 (6): e39202.

Mora-Rodriguez R. Influence of aerobic fitness on thermoregulation during exercise in the heat. Exerc Sport Sci Rev 2012: 40 (2): 79-87.

Morris J, Nevill M, Lakomy H, Nicholas C, Williams C. Effect of a hot environment on performance of prolonged, intermittent, high-intensity shuttle running. J Sports Sci 1998: 16 (3): 677-686.

Morris J, Nevill M, Thompson D, Collie $\mathrm{J}$, Williams C. The influence of a $6.5 \%$ carbohydrate-electrolyte solution on performance of prolonged intermittent high-intensity running at $30^{\circ} \mathrm{C}$. J Sports Sci 2003: 21 (5): 371-381. 
Sprinting in hot ambient temperature

Morris J, Nevill M, Williams C. Physiological and metabolic responses of female games and endurance athletes to prolonged, intermittent, high-intensity running at 30 degrees and 16 degrees $\mathrm{C}$ ambient temperatures. Eur J Appl Physiol 2000: 81 (1-2): 84-92.

Morris JG, Nevill ME, Boobis LH, Macdonald IA, Williams C. Muscle metabolism, temperature, and function during prolonged, intermittent, high intensity running in air temperatures of $33^{\circ} \mathrm{C}$ and $17^{\circ} \mathrm{C}$. Int $\mathrm{J}$ Sports Med 2005: 26 (10): 805-814.

Nybo L, Girard O, Mohr M, Knez WL, Voss S, Racinais S. Markers of muscle damage and performance recovery after exercise in the heat. Med Sci Sports Exerc 2013: 45 (5): 860-868.

Nybo L, Rasmussen P, Sawka MN. Performance in the heat - Physiological factors of importance for hyperthermia-induced fatigue. Compr Physiol 2014: 4: 1-33.

Périard J, Racinais S, Knez WD, Herrera C, Christian RJ, Girard O. Coping with heat stress during match-play tennis: does an individualised hydration regimen enhance performance and recovery? Br J Sports Med 2014b: 48 (1): i64-i70.

Périard JD, Christian RJ, Knez WL, Racinais S. Voluntary muscle and motor cortical activation during progressive exercise and passively induced hyperthermia. Exp Physiol 2014a: 99 (1): 136-148.

Périard JD, Cramer MN, Chapman PG, Caillaud C, Thompson MW. Neuromuscular function following prolonged intense self-paced exercise in hot climatic conditions. Eur J Appl Physiol 2011: 111 (8): 1561-1569.

Petersen C, Portus M, Pyne D, Dawson B, Cramer M, Kellett A. Partial heat acclimation in cricketers using a 4-day high intensity cycling protocol. Int $\mathrm{J}$ Sports Physiol Perform 2010: 5 (4): 535-545.

Pullinger SA, Brocklehurst EL, Iveson RP, Burniston JG, Doran DA, Waterhouse JM, Edwards BJ. Is there a diurnal variation in repeated sprint ability on a non-motorised treadmill? Chronobiol Int 2014: 31 (3): 421-432.

Racinais S, Blonc S, Oska J, Hue O. Does the diurnal increase in central temperature interact with pre-cooling or passive warm-up of the leg? J Sci Med Sport 2009: 12 (1): 97-100.

Racinais S, Connes P, Bishop D, Blonc S, Hue O. Morning vs evening power output and repeated-sprint ability. Chronobiol Int 2005: 22 (6): 1029-1039.

Racinais S, Hue O, Blonc S. Time-of-day effects in anaerobic muscular power in a warm environment. Chronobiol Int 2004: 21 (3): 485-495

Racinais S, Mohr M, Buchheit M, Voss SC, Gaoua N, Grantham J, Nybo L. Individual response to short-term heat acclimatization as predictors of football performance in a hot, dry environment. Br J Sports Med 2012: 46 (11): 810-815.

Racinais S, Perrey S, Denis R, Bishop D. Maximal power, but not fatigability, is greater during repeated sprints performed in the afternoon. Chronobiol Int 2010: 27 (4): 855-864.

Russel M, West DJ, Harper LD, Cook CJ, Kilduff LP. Half-time strategies to enhance second half performance in team-sports players. A review and recommendations. Sports Med 2015. [Epub ahead of print]. doi: 10.1007/s40279-014-0297-0

Sargeant AJ. Effect of muscle temperature on leg extension force and short-term power output in humans. Eur J Appl Physiol 1987: 56 (6): 693-698.

Sargeant AJ, Rademaker A. Human muscle power in the locomotory range of contraction velocities increases with temperature due to an increase in power generated by type I fibres. J Physiol 1996: 491: 128P.

Sawka MN, Leon LR, Montain SJ, Sonna LA. Integrated physiological mechanisms of exercise performance, adaptation, and maladaptation to heat stress. Compr Physiol 2011: 1 (4): 1883-1928.

Shirreffs SM. Hydration: special issues for playing football in warm and hot environments. Scand J Med Sci Sports 2010: 20 (3): 90-94.

Skein M, Duffield R. The effects of fluid ingestion on free-paced intermittent-sprint performance and pacing strategies in the heat. J Sports Sci 2010: 28 (3): 299-307.

Sleivert GG, Cotter JD, Roberts WS, Febbraio MA. The influence of whole-body vs torso pre-cooling on physiological strain and performance of high-intensity exercise in the heat. Comp Biochem Physiol 2001: 128 (4): 657-666.

Spencer M, Bishop D, Dawson B, Goodman C. Physiological and metabolic responses of repeated-sprint activities. Sports Med 2005: 35 (12): 1025-1044.

Steinen GJM, Kiers JL, Bottinelli R, Reggiani C. Myofibrillar ATPase activity in skinned human skeletal muscle fibres: fibre types and temperature dependence. J Physiol 1996: 493 (Pt 2): 299-307.

Sunderland C, Morris J, Nevill M. A heat acclimation protocol for team sports. Br J Sports Med 2008: 42 (5): 327-333.
Sunderland C, Nevill ME. High-intensity intermittent running and field hockey skill performance in the heat. J Sports Sci 2005: 23 (5): 531-540.

Tabata I, Irisawa K, Kouzaki M, Ishimura K, Ogita F, Miyachi M. Metabolic profile of high intensity intermittent exercises. Med Sci Sports Exerc 1997: 29 (3): 390-395.

Tatterson AJ, Hahn AG, Martin DT, Febbraio MA. Effects of heat stress on physiological responses and exercise performance in elite cyclists. J Sci Med Sport 2000: 3 (2): 186-193.

Taylor NA. Human heat adaptation. Compr Physiol 2014: 4 (1): 325-365.

Tyler CJ, Sunderland C, Cheung SS. The effect of cooling prior to and during exercise on exercise performance and capacity in the heat: a meta-analysis. Br J Sports Med 2015: 49 (1): 7-13.

Volek JS, Mazzetti SA, Farquhar WB, Barnes BR, Gomez AL, Kraemer WJ. Physiological responses to short term exercise in the heat after creatine loading. Med Sci Sports Exerc 2001: 33 (7): 1101-1108.

Watson G, Judelson DA, Armstrong LE, Yeargin SW, Casa DJ, Maresh CM. Influence of diuretic-induced dehydration on competitive sprint and power performance. Med Sci Sports Exerc 2005: 37 (7): 1168-1174.

White AC, Salgado RM, Schneider S, Loeppky JA, Astorino TA, Mermier $\mathrm{CM}$. Does heat acclimation improve exercise capacity at altitude? A cross-tolerance model. Int J Sports Med 2014: 35 (12): 975-981.

Yaicharoen P, Wallman K, Bishop DJ, Morton A. The effect of single and intermittent-sprint performance. J Sports Sci 2012a: 30 (8): 833-840.

Yaicharoen P, Wallman K, Morton A, Bishop DJ. The effect of warm-up on intermittent sprint performance and selected thermoregulatory parameters. J Sci Med Sport 2012b: 15 (5): 451-456.

Yaicharoen P, Wallman K, Morton A, Bishop DJ, Grove RJ. The effects of warm-up on intermittent sprint performance in a hot and humid environment. J Sports Sci 2012c: 30 (10): 967-974.

Yoshida T, Takanishi T, Nakai S, Yorimoto A, Morimoto T. The critical level of water deficit causing a decrease in human exercise performance: a practical field study. Eur J Appl Physiol 2002: 87 (6): 529-534.

Zois J, Bishop D, Fairweather I, Ball K, Aughey RJ. High-intensity re-warm-ups enhance soccer performance. Int $\mathbf{J}$ Sports Med 2013: 34 (9): 800-805. 